Björn Ellger

Lies Langouche

Milan Richir

Yves Debaveye

Ilse Vanhorebeek

Paul A. Van Leeuwen

Greet Van den Berghe

\title{
Modulation of regional nitric oxide metabolism: Blood glucose control or insulin?
}

Published online: 24 May 2008

(C) Springer-Verlag 2008

The online version of the original article can be found at doi:10.1007/s00134-008-1118-4.

B. Ellger · L. Langouche · Y. Debaveye · I. Vanhorebeek ·

G. Van den Berghe

Department of Intensive Care Medicine,

Katholieke Universiteit Leuven,

3000 Leuven, Belgium

B. Ellger $(\bullet)$

Department of Anesthesiology and Intensive Care Medicine,

University Hospital,

48149 Muenster, Germany

e-mail: ellger@anit.uni-muenster.de

Tel.: +49-251-8347255

Fax: +49-251-88704

M. Richir · P. A. Van Leeuwen

Department of Surgery,

VU University Medical Center,

1007 MB Amsterdam, The Netherlands
Intensive Care Med (2008)

DOI 10.1007/s00134-008-1118-4

A footnote regarding the contributions of the first two authors was erroneously omitted in typesetting.

The note is reproduced here.

Björn Ellger and Lies Langouche contributed equally to this work. 